\title{
The Moderating Effect of Leader-member Exchange on the Job Insecurity- Organizational Commitment Relationship
}

\author{
Sanman Hu, Bin Zuo \\ College of Psychology, Huazhong Normal University, Wuhan, China \\ 430079, sanman_hu@yahoo.com.cn
}

\begin{abstract}
Job insecurity has become an important issue for society and organizations in the last decades due to uncertain economic conditions, global competition, and the advancement of information technology. As job insecurity have detrimental consequences for employees and organizations, it is vital to identify variables that could buffer against the negative effects of job insecurity. In this study, we examined the moderating effect of Leadermember exchange on the relation between job insecurity and organizational commitment. Data collected from 314 employees indicated that the negative relationship between qualitative insecurity and affective commitment was alleviated as Leader-member exchange increased. Furthermore, the positive relation between quantitative insecurity and continuance commitment decreased as Leader-member exchange increased.
\end{abstract}

\section{Introduction}

Working life has been subject to dramatic change over the past two decades as economic recessions, new information technology, industrial restructuring, and an accelerated global competition unceasingly have proved to be crucial and abiding factors influencing the nature of work and organization. In their struggle for survival, organizations are faced with the necessity of making their operations more effective with fewer resources, especially human resources. These unpredictable economic situation and tougher competitive standards have resulted in downsizing, mergers, acquisitions, and other types of structural change, all of which tend to produce increased feelings of insecurity among the workers, not only pertaining to their jobs but also about the future in general [1]. As a result, job insecurity has received growing recognition of researchers [2].

Please use the following format when citing this chapter:

Hu, S., Zuo, B., 2007, in IFIP International Federation for Information Processing, Volume 252, Integration and Innovation Orient to E-Society Volume 2, cts. Wang. W., (Boston: Springer), pp. 505-513. 


\section{Theoretical backgrounds and hypothesis}

Job insecurity is a subjective phenomenon, in contrast to actual of job loss, it refers to the anticipation of this stressful event in such a way that the nature and continued existence of one's job are perceived to be at risk [3]. However, Greenhalgh and Rosenblatt [4], who were the first to introduce a multidimensional definition, noted: "Loss of valued job features is an important but often overlooked aspect of job insecurity". Later on, a number of researchers agreed with this opinion. For instance, Hellgren, Sverke, and Isaksson [2] made a distinction between quantitative job insecurity (worries about losing the job itself) and qualitative job insecurity (worries about losing important job features, including future career opportunities, stimulating job content, competence exertion, pay development).

In a meta-analysis of job insecurity, Sverke, Hellgren, \& Naswall [1] summed up it's potential consequences. The results indicated that job insecurity has detrimental consequence for employees' job attitudes, organizational attitudes, health, and, to some extent, their behavioral relationship with the organization. Job insecurity has already been considered as an important stressor in work field at the present time [5]. Hence, the question of how to reduce these negative consequences is a high priority now. The answer of this question will deepen our understanding of mechanism of job insecurity's negative effect, and contribute to the solutions alleviating most impact of job insecurity.

Considerable research attention has been given to how job insecurity is related to organizational attitudes, such as commitment, which is a very important organizational attitude and also has received a lot of attention. In most of the studies, organizational commitment has been found to have a moderate negative association with job insecurity [1], so finding variables which can alleviate job insecurity's negative impact on commitment is in urgent need. On the other hand, some studies have reported a strong negative relationship or no significant relation at all [1]. Thus, because the strengths of correlations vary across studies, it is likely some other factors influence the relationships between job insecurity and organizational commitment. Owing to the above reasons, examining potential moderators between job insecurity and commitment is not only meaningful in practice, also essential for theoretical development.

The Leader-member exchange (LMX) model proposed by Graen and UhI-Bien explains that leaders develop unique one-on-one relationships with different subordinates. High-quality LMX, sometimes called "in-group", is characterized by increased levels of information exchange, mutual support, informal influence, professional trust, greater negotiating latitude, and input in decisions. Lower quality LMX, sometimes called "out-group", is characterized by more formal supervision, less support, and less trust and attention from the leader [6]. Perhaps the most important distinction between the differences in Leader-member relationships is the degree of emotional support and task challenge given to the member.

Joelson and Wahlquist [7] suggested that job insecurity is burdening because of prolonged uncertainty. While two factors: unpredictability and uncontrollability are considered the probable reasons in explaining the harmful impact of "uncertainty". First of all, job insecurity means unpredictability: what will happen in the future is 
unclear for those concerned. This makes it difficult to react appropriately. Besides, uncontrollability also plays a crucial role. The lack of control, or the feeling of powerlessness towards the threat, is considered by some authors to be the core of the phenomenon of job insecurity [8]. Given above mentioned nature and character of LMX, one can expect that favorable LMX will play a role in helping employees decrease unpredictability and increase controllability, also contributing to their level of commitment to the organization even though the level of job insecurity felt by employees is high, so the following two hypotheses are proposed.

H1: Leader-member exchange will moderate the relationship between quantitative job insecurity and organizational commitment. The negative relationship between quantitative job insecurity and organizational commitment will be stronger for employees with low LMX than those with high LMX.

H2: Leader-member exchange will moderate the relationship between qualitative job insecurity and organizational commitment. The negative relationship between qualitative job insecurity and organizational commitment will be stronger for employees with low LMX than those with high LMX.

\section{Methods}

\subsection{Subjects}

Participants were 400 full-time employees from 10 enterprises in Wuhan, Guangzhou, and Ningbo city in China. 314 questionnaires (response rate $=78.5 \%$ ) were returned. The total group of respondents can be characterized as follows: 78 percent were men and 69 percent subjects below 30 years; 42 percent have high school diploma, 25 percent have junior college diploma, 24 percent have university diploma, 9 percent have master degree or above; 38 percent were staff member, 50 percent were supervisor, 12 percent were manager. 26 percent were from stateowned enterprise, 24 percent were form foreign-funded enterprise, 50 percent were from private enterprise.

\subsection{Measures}

Job insecurity. The two dimensions of job insecurity scale developed by Hellgren, Sverke, and Isaksson [2] were used, and scored on a 5-point Likert scale (1=strongly disagree; $5=$ strongly agree). Quantitative job insecurity was measured by three items, sample items include:" I am worried about having to leave my job before I would like to" and "I feel uneasy about losing my job in the near future". Qualitative job insecurity was measured by four items, sample items inciude:" My future career opportunities in the organization are favorable" (Reverse coded). The internal consistency reliability was satisfactory for both quantitative (alpha $=0.68$ ) and qualitative job insecurity (alpha $=0.81$ ).

Leader-member exchange. The LMX-7 scale, developed by Graen and Uhl-Bien (1995), was designed to measure the perception of quality of exchange relationships between the supervisor and the subordinate [6]. In our research, it also scored on a 5- 
point Likert scale (1=strongly disagree; $5=$ strongly agree). Sample items include: "I know how satisfied my supervisor is with what I do". The internal consistency reliability was satisfactory (alpha $=0.80$ ).

Organizational commitment. The three dimensions of organizational commitment scale developed by Meyer, Allen, and Smith [9] were used, and scored on a 5-point Likert scale ( $1=$ strongly disagree; $5=$ strongly agree). Affective commitment, normative commitment, and continuance commitment were measured by six items separately. The internal consistency reliability for these commitments were acceptable (alpha were $0.70,0.64$, and 0.69 accordingly).

\subsection{Data Analysis}

To test the hypothesized moderators, we conducted moderated regression analyses. Specially, we entered the control variables in the first step, followed by three independent variables (i.e. quantitative insecurity, qualitative insecurity, and leadermember exchange) in the second step, and all of the two-way interaction terms in the third step. Using this analysis, one would expect to find that the interaction effects of job insecurity and LMX explain an additional significant amount of the variance beyond their main effects. To reduce multicollinearity among the interaction terms, we centered the component scales and computed the interaction terms using the centered scores [10].

\section{Results}

\subsection{Descriptive statistics and correlations}

Descriptive statistics, correlation coefficients among the study variables are displayed in Table 1. This tale revealed several important points. First, quantitative job insecurity have significant correlations with normative and continuance commitment. Second, qualitative job insecurity have significant correlations with affective and normative commitment. Third, LMX also have significant correlations with affective commitment and normative commitment.

Table 1. Descriptive statistics and correlations among variables

\begin{tabular}{llllllll}
\hline variables & $M$ & $S D$ & 1 & 2 & 3 & 4 & 5 \\
\hline 1.Gender & 1.22 & .413 & - & & & & \\
2.Age & 1.312 & .464 & $-.164^{* *}$ & - & & & \\
3.Educational level & 1.99 & 1.008 & $-.148^{*}$ & -.104 & - & & \\
4.Position & 1.75 & .661 & $-.128^{*}$ & $.310^{* *}$ & .095 & - & \\
5.Company type & 2.24 & .837 & $-.038^{*}$ & $-.135^{*}$ & .054 & .420 & - \\
6.Quantitative insecurity & 2.963 & .839 & -.111 & $.192^{* *}$ & $-.185^{* *}$ & $.250^{* *}$ & .014 \\
7.Qualitative insecurity & 2.754 & .767 & $-.172^{* *}$ & $-.133^{*}$ & .054 & .008 & .106 \\
8. Leader-member exchange & 3.598 & .609 & -.043 & .050 & -.036 & .027 & -.078 \\
9. Affective commitment & 3.208 & .587 & -.073 & -.044 & -.097 & -.056 & .020 \\
\hline
\end{tabular}


Organizational Commitment Relationship

\begin{tabular}{llllllll}
\hline 10.Normative commitment & 3.001 & .626 & -.052 & .033 & -.102 & .105 & -.028 \\
11.Continuance commitment & 2.758 & .629 & -.038 & $.165^{* *}$ & -.067 & .104 & $-.162^{* *}$ \\
& & & & & & & \\
\hline variables & 6 & 7 & 8 & 9 & 10 & 11 & \\
\hline 6.Quantitative insecurity & - & & & & & & \\
7.Qualitative insecurity & $-.251^{* *}$ & - & & & & \\
8. Leader-member exchange & $.111^{*}$ & $-.303^{* *}$ & - & & & \\
9. Affective commitment & .103 & $-.465^{* *}$ & $.379^{* *}$ & - & & & \\
10.Normative commitment & $.207^{* *}$ & $-.501^{* *}$ & $.285^{* *}$ & $.480^{* *}$ & - & & \\
11.Continuance commitment & $.392^{* *}$ & -.036 & .005 & $-.150^{* *}$ & $.152^{* *}$ & & \\
\hline
\end{tabular}

Note. ${ }^{*} \mathrm{p}<0.05,{ }^{* *} \mathrm{p}<0.01$.

\subsection{Moderating effects of Leader-member exchange between job insecurity and commitment}

A summary of the results of moderated regression analyses is shown in Table 2. As shown in this table, after controlling some demographic variables, quantitative job insecurity was still a strong predictor of continuance commitment $(\beta=0.324$, $\mathrm{t}=5.437, \mathrm{p}=0.000$ ), and qualitative insecurity was a strong positive predictor of affective commitment and normative commitment $(\beta=-0.400, t=-7.208, p=0.000 ; \beta=-$ $0.451, t=-8.137, \mathrm{p}=0.000$ ).

Table 2 Results of moderated regression analyses

\begin{tabular}{lllll}
\hline \multirow{2}{*}{ variables } & & \multicolumn{3}{l}{ Organizational commitment } \\
\cline { 3 - 5 } & & $\begin{array}{l}\text { Affective } \\
\text { commitment }\end{array}$ & $\begin{array}{l}\text { Normative } \\
\text { commitment }\end{array}$ & $\begin{array}{l}\text { Continuance } \\
\text { commitment }\end{array}$ \\
\hline Step1: & Gender & -0.095 & -0.041 & 0.016 \\
& Age & -0.020 & -0.055 & 0.006 \\
& Educational level & -0.128 & -0.114 & -0.011 \\
& Position & -0.058 & $0.158^{*}$ & $0.141^{*}$ \\
& foreign-funded enterprise & -0.028 & -0.028 & 0.101 \\
& private enterprise & -0.011 & -0.136 & $-0.222^{* *}$ \\
$R^{2}$ & & 0.024 & 0.036 & $0.097^{* *}$ \\
Step2: & Quantitative insecurity & -0.022 & 0.046 & $0.324^{* *}$ \\
& Qualitative insecurity & $-0.400^{* *}$ & $-0.451^{* *}$ & 0.112 \\
& Leader-member exchange & $0.248^{* *}$ & $0.128^{*}$ & -0.021 \\
$\triangle R^{2}$ & & $0.258^{* *}$ & $0.247^{* *}$ & $0.090^{* *}$ \\
Step3: & Quantitative insecurity $\times \mathrm{LMX}$ & -0.051 & -0.032 & 0.111 \\
& Qualitative insecurity $\times \mathrm{LMX}$ & $0.138^{* *}$ & 0.026 & 0.002 \\
$\triangle R^{2}$ & & $0.021^{*}$ & 0.002 & 0.011 \\
\hline
\end{tabular}

Also as shown in table 2, after the interaction terms of two kinds of job insecurity and leader-member exchange entering the regression, the interaction effect of quantitative job insecurity and LMX on continuance commitment was nearly 
significant $(\beta=0.111, t=1.947, p=0.053)$, and the interaction effect of qualitative insecurity and LMX on affective commitment was significant $(\beta=0.138, t=2.582, p$ $=0.010$ ). These results indicated the relationship between quantitative job insecurity and continuance commitment, and the relationship between qualitative insecurity and affective commitment are all moderated by LMX. Furthermore, the amount of explained variance for each interaction term is above the range expected (.01-.03) for moderator effects in field studies [11], which means the nature of two interaction effect needs thorough theoretic analyze and also have practical implications.
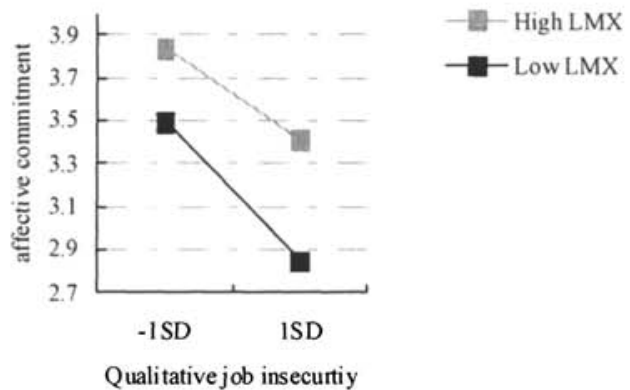

Figure. 1. Interactive effect of qualitative insecurity and LMX on affective commitment

We assessed the nature of above two interaction by plotting values of plus and minus on standard deviation from the means on two kinds of job insecurity and leader-member exchange. Figure 1 depicts graphically the interaction of LMX on the relationship between qualitative insecurity and affective commitment. As shown in the figure, the directions of the relationship were in line with Hypothesis 2 in that the slope of the regression line of affective commitment on qualitative insecurity for low LMX was steeper than the slope of the regression for high LMX. Thus, we conclude that the negative relationship between qualitative insecurity and affective commitment was stronger for those who perceived low LMX and weaker for those who perceived high LMX.
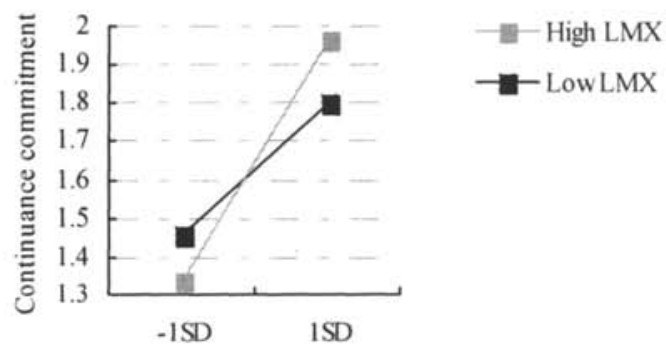

Quantitative job insecurity

Figure 2. Interactive effect of quantitative job insecurity and LMX on continuance 
commitment

Figure 2 revealed that, the most unexpected finding is, as the level of quantitative job insecurity increased, employee's continuance commitment also increased, and contrary to Hypothesis 1 , the relationship between quantitative job insecurity and continuance commitment became weaker for those with low LMX.

\section{Discussion}

A perceived loss of continuity in a job situation can span the range from threats of imminent job loss to loss of important job features, these different aspects may evoke divergent reactions. To date, only a few studies report relationships of different job insecurity dimensions and outcomes $[12,13,2]$. Clearly, further research is needed to understand the potentially differential effects of various dimensions of job insecurity. Meanwhile, previous researches about job insecurity and commitment were also lack of more specific exploration toward different dimensions of commitment. Our results indicated that, quantitative job insecurity and qualitative job insecurity indeed have very different impact on different dimensions of commitment. Quantitative insecurity was a positive predictor of continuance commitment, while qualitative insecurity was a negative predictor of affective commitment and normative commitment.

Continuance commitment is based on an economic need to stay with an organization rather than an emotional attachment. Hence, to employees, it is reasonable that the more worries about job loss, the more continuance commitment toward organization. However the damage of employment quality, such as lack of career opportunities, stimulating job content, competence exertion, pay development et al., will definitely impair the relative strength of an individual's identification with and involvement in a particular organization, and the willingness of abiding organizational rules.

While researchers advocate the importance of effective leadership to enact and support change, previous studies have not focused on the moderating effects of leadership on the relationship between job insecurity and employee outcomes. Therefore, the main focus of the present study was to explore the role Leadermember exchange relationship plays as a buffer against the negative impact of job insecurity on employee's organizational commitment. Results of moderated regression analyses indicated that the negative relationship between qualitative insecurity and affective commitment was alleviated as Leader-member exchange increased, while the positive relationship between quantitative insecurity and continuance commitment decreased as Leader-member exchange increased.

At every stage of its development, with deterioration of employment quality, what organization urgently needs is all members' concerted effort. Obviously, low level of affective commitment will make it difficult for members to complete their task and accomplish their mission. Fortunately, our results, to some degree, identify that favorable LMX can help employees maintain affective commitment to the organization despite high level of job insecurity. 
For developing and maintaining favorable Leader-member exchange relation with their supervisor, those "in-group" members pay harder working. Hence, their cost of dimission will be higher than those "out-group". Meanwhile, due to supervisors' special trust and support, "in-group" members will also attach greater importance to their jobs. As a result, "in-group" members with great concern about losing present job will have greater continuance commitment than ever. During developing and transforming stage, this kind of well-established LMX can have a great deal of positive effect, such as making member undisturbed and wishful for organizational change. However, the strength of continuance commitment in members with low LMX didn't significantly enhance. They may hold a fence-sitting attitude. Etzioni characterized these members with "alienative involvement" toward organization [14]. It could expect that this kind of low continuance commitment would probably not only destroy group's cohesive force and also reduce organizational efficiency.

\section{References}

1. M. Sverke, J. Hellgren, K. Naswall, No security: a meta-analysis and review of job insecurity and its consequences, Journal of occupational health psychology. 7(3), 242-264 (2002).

2. J. Hellgren, M. Sverke, K. Isaksson, A tow-dimensional approach to job insecurity: consequences for employee attitudes and well-being, European Journal of Work and Organizational Psychology. 8(2), 179-195 (1999).

3. M. Sverke, J. Hellgren, The nature of job insecurity: understanding employment uncertainty on the brink of a new millennium, Applied psychology: an international review. 51(1), 23-42, (2002).

4. L. Greenhalgh, Z. Rosenblatt, Job security: toward conceptual clarity, Academy of Management Review. 9(3), 438-448 (1984).

5. A. S. Mak, J. Mueller, Job insecurity, coping resources and personality dispositions in occupational strain, Work \& Stress. 14(4), 312-328, (2000).

6. A. Castanon, Managing traumatic change: the role of leadership as a buffer against the negative impact of job insecurity on employment outcomes, Alliant International University, Los Angeles, California. Unpublished doctoral dissertation. 2005,p.31.

7. L. Joelson, L. Wahlquist, The psychological meaning of job insecurity and job loss: results of a longitudinal study, Social science and medicine. 25(2), 179-182, (1987)

8. H. De Witte, Job insecurity and psychological well-being: review of the literature and exploration of some unresolved issues, European Journal of Work and Organizational Psychology. 8(2), 155-177 (1999).

9. J. P. Meyer, N. J. Allen, C. A. Smith, Commitment to organizations and occupations: extension and test of a three-component conceptualization, Journal of Applied Psychology. 78(4), 538-551 (1993)

10. M. C. Andrews, L. A. Witt, K. M. Kacmar, The interactive effects of organizational politics an exchange ideology on manager ratings of retention, Journal of vocational behavior. $62,357-369$ ( 2003). 
11. Z. S. Byrne, C. Kacmar, J. Stoner, W. Hochwarter, The relationship between perceptions of politics and depressed mood at work: unique moderators across three levels, Journal of Occupational Health Psychology. 10(4), 330-343, (2005).

12. M. Sverke, J. Hellgren, K. Naswall, Job insecurity: a literature review, http//www. arbetslivsinstitutet.se/saltsa/2006/wlr2006_01.pdf

13. S. J. Ashford, C. Lee, P. Bobko, Content, causes, and consequences of job insecurity: a theory-based measure and substantive test, Academy of Management Journal. 32(4), 803-829 (1989).

14. A. Lord, J. Hartley, Organizational commitment and job insecurity in a changing public service organization, European Journal of Work and Organizational Psychology. 7(3), 341354 (1999). 